\title{
Effect of Collagen Type I or Human Fibronectin on Imatinib Cytotoxicity in Oral Squamous Cell Carcinoma
}

\author{
Masahiko Morioka1,2*, Mai Hazekawa ${ }^{1 *}$, Tomoyo Kawakubo-Yasukochi' ${ }^{1}$, \\ Takuya Nishinakagawa ${ }^{1}$, Seiji Nakamura², Manabu Nakashima ${ }^{1 \#}$ \\ ${ }^{1}$ Department of Immunological and Molecular Pharmacology, Faculty of Pharmaceutical Science, \\ Fukuoka University, Fukuoka, Japan \\ ${ }^{2}$ Section of Oral and Maxillofacial Oncology, Division of Maxillofacial Diagnostic and Surgical Sciences, \\ Faculty of Dental Science, Kyushu University, Fukuoka, Japan \\ Email:"nakashim@adm.fukuoka-u.ac.jp
}

Received 9 June 2016; accepted 10 July 2016; published 13 July 2016

Copyright (C) 2016 by authors and Scientific Research Publishing Inc.

This work is licensed under the Creative Commons Attribution International License (CC BY). http://creativecommons.org/licenses/by/4.0/

c) (i) Open Access

\begin{abstract}
Extracellular matrix (ECM) components are critical for all aspects of cell proliferation, adhesion, and morphological alteration. Recent progress has yielded multiple molecular drugs that specifically target gene products which are expressed at high levels in tumor cells. We investigated whether the sensitivity of tumor cells to molecular target drugs could be altered when cells were cultured on surfaces with various coating conditions such as lysine, laminin, Matrigel, collagen type I, and human fibronectin (HFN). This study evaluates the $\mathrm{IC}_{50}$ values of imatinib in oral squamous cell carcinoma (OSCC) cell lines when cells are cultured on plates coated with ECM components such as collagen type I and HFN. Four OSCC cell lines-SQUU-A, SQUU-B, SAS, and NAare used. Cell proliferation was assessed using WST-8 reagent. Collagen type I and HFN significantly enhanced OSCC cell proliferation compared with control. Imatinib cytotoxicity was demonstrated following culture of OSCCs in culture plates coated with collagen type I or HFN. However, there were no significant changes in imatinib IC $_{50}$ values between collagen type I and HFN. These results indicate that some molecular target drugs exhibit cancer cell cytotoxicity without being influenced by cell environment factors such as the ECM. These results may aid in the search for molecular target drugs to apply in the clinical chemotherapy of OSCC.
\end{abstract}

\section{Keywords}

Collagen Type I, Human Fibronectin, Imatinib Cytotoxicity, Oral Squamous Cell Carcinoma

\footnotetext{
*These authors contributed equally to this work.

${ }^{\#}$ Corresponding author.
} 


\section{Introduction}

Oral squamous cell carcinoma (OSCC) currently is treated largely by surgery and/or irradiation, although few unequivocal controlled trials of treatment modalities have been conducted. Photodynamic and chemotherapy have occasional applications, and there is an increased use of chemotherapy, [1] [2] including targeted therapy. Chemotherapy has been used in the treatment of malignant tumors for many years. Anti-cancer drugs exhibit many mechanisms of action, including DNA synthesis antagonism and cell division disruption, but most require that the tumor cells are actively dividing. However, this targeting of actively-dividing cells by anti-cancer drugs leads to undesirable side effects. The resolution or minimization of these side effects would be of great clinical benefit [3]. Recently, various gene products associated with carcinogenesis and malignant transformation have been elucidated and molecular target-based medicine has been pursued. Molecular target drugs are developed following identification of gene products which are expressed at high levels in specific tumor cells. These molecular target drugs effectively induce selective toxicity in cancer cells, and are therefore expected to possess fewer side effects than conventional chemotherapeutic agents [4]. The molecular target drug imatinib is originally designed as a therapeutic for chronic myeloid leukemia (CML). Imatinib acts by inhibiting cell proliferation through targeting of Bcr-Abl tyrosine kinase (TK). Additionally, imatinib also inhibits TK receptors such as platelet-derived growth factor (PDGF), vascular endothelial growth factor, and KIT, and functions against gastrointestinal stromal tumors, Philadelphia chromosome-positive acute lymphocytic leukemia, and myelodysplastic/myeloproliferative diseases associated with platelet-derived growth factor receptor (PDGFR) gene rearrangements [5]-[9]. Molecular target drugs bind specifically to molecules present on tumor cells, so they do not show effective drug action when these receptors are altered, obscured, or absent. Therefore, the local environment may affect the susceptibility of tumor cells to molecular target drugs by influencing receptor molecule expression levels. The extracellular matrix (ECM) provides critical support for the vascular endothelium. The ECM also provides a scaffold essential for maintaining the vascular organization primarily through adhesive interactions with integrins on the endothelial cell surface [10]. The establishment of fibrin-rich clots in wound spaces forms a provisional ECM, and clotting is accompanied by the activation of platelets, neutrophils, and macrophages. These cells ultimately resolve wounds by promoting the synthesis, remodeling, and contraction of the matrix [11]. Additionally, these cells communicate with each other largely through the secretion of soluble factors. Fibroblasts are stimulated by PDGF ligands, which are released as a bolus by activated platelets [12]. Furthermore, integrin-mediated adhesion influences cell survival and may prevent programmed cell death [13].

We investigated whether the cytotoxic activity of imatinib could be influenced by culture vessel coating conditions. We calculated $\mathrm{IC}_{50}$ values following the addition of various concentrations of imatinib to OSCC cultures under collagen type I or human fibronectin (HFN) coating conditions.

\section{Materials and Methods}

\subsection{Materials}

\subsubsection{Cell Line and Cell Culture}

The human OSCC cell lines, SQUU-A, SQUU-B, SAS, and NA were derived from human tongue samples. SQUU-A and SQUU-B cell lines were established from local recurrences of an OSCC lesion in the same patient. Cervical lymph node metastasis was detected in mice orthotopically implanted with SQUU-B (86.7\%), but not in those with SQUU-A (0\%) [14]. SAS cells were derived from a poorly-differentiated human tongue OSCC lesion [15]-[17]. NA cells were derived from a poorly-differentiated tongue carcinoma and produce fibronectin [18]. All cell lines were maintained in Dulbecco's Modified Eagle's Medium (DMEM) (Nacalai Tesque Inc., Kyoto, Japan) containing $10 \%$ fetal calf serum (Biowest, France) at $37^{\circ} \mathrm{C}$ on cell culture plate in a humidified atmosphere with $95 \%$ air and $5 \% \mathrm{CO}_{2}$.

\subsubsection{Reagents}

Imatinib (Focus Biomolecules, Plymouth Meeting, PA, USA) was diluted in $50 \mathrm{mM}$ dimethylsulfoxide (DMSO; Sigma-Aldrich Inc., St. Louis, MO, USA) and stored at $-20^{\circ} \mathrm{C}$. DMSO was then present at $0.1 \%$ in experimental samples. Six coating materials were prepared. Type I bovine collagen (Collagen type I) was purchased from Thermo Fisher Scientific Inc. (Waltham, MA, USA). HFN and Matrigel were purchased from Corning Inc. (Corning, NY, USA). Laminin, Poly-L-Lysine, and Poly-D-Lysine, were purchased from Sigma-Aldrich Inc. (St. 
Louis, MO, USA).

\subsection{Methods}

\subsubsection{Coating Method}

Flat-bottomed untreated 96-well plates were coated with $50 \mu \mathrm{L} /$ well phosphate-buffered saline (PBS; Gibco-BRL, Grand Island, NY) as negative control or $50 \mu \mathrm{L} /$ well coating material and incubated for $2 \mathrm{~h}$ at room temperature. After incubation, plates were washed twice with PBS and DMEM was then added [19]. Cell culture plates were coated with $5 \mu \mathrm{g} / \mathrm{cm}^{2}$ collagen type I diluted in $20 \mathrm{mM} \mathrm{CH}_{3} \mathrm{COOH}$. Coating concentrations of HFN, Laminin, poly-D-Lysine, poly-L-Lysine, and Matrigel were 1 - $5 \mu \mathrm{g} / \mathrm{cm}^{2}, 1-2 \mu \mathrm{g} / \mathrm{cm}^{2}, 2-4 \mu \mathrm{g} / \mathrm{cm}^{2}, 2 \mu \mathrm{g} / \mathrm{cm}^{2}$, and $50 \mu \mathrm{g} / \mathrm{cm}^{2}$, respectively, all diluted with $\mathrm{dH}_{2} \mathrm{O}$.

\subsubsection{Cell Proliferation Assay}

After plate coating and aspiration of DMEM, OSCC cells were seeded into each well at 5, 10, or $20 \times 10^{3}$ cells/well/200 $\mu \mathrm{L}$ DMEM). After $24 \mathrm{~h}$ incubation at $37^{\circ} \mathrm{C}$ and $5 \% \mathrm{CO}_{2}$, cells under each culture condition were observed using a microscope (EVOS, Thermo Fisher Scientific Inc.). The number of active cells was measured using WST-8. Briefly, $20 \mu \mathrm{L}$ WST-8 dye was added to each well and absorbance at 450/655 nm measured using a microplate reader after a 3-h incubation. A blank well containing culture medium alone served as a control in all experiments.

\subsubsection{Cytotoxicity Assay}

After coating and initial seeding and culture of OSCC cells, the culture medium was removed and replaced with imatinib-containing medium. Following $24 \mathrm{~h}$ in a tissue culture incubator, $20 \mu \mathrm{L} /$ well of WST-8 dye was added to each well for $3 \mathrm{~h}$ and plates were read at $450 \mathrm{~nm} / 655 \mathrm{~nm}$. The cell survival rate was calculated using the formula below [20]. IC $_{50}$ values were calculated by linear approximation regression of percent survival versus drug concentration.

$$
\text { Cell survival rate }(\%)=(a-c) /(b-c) \times 100
$$

( $\mathrm{a}=$ absorbance at each imatinib concentration, $\mathrm{b}=$ absorbance at $0 \mu \mathrm{M}$ of imatinib, $\mathrm{c}=$ absorbance of blank)

\subsection{Statistical Analysis}

All experiments were performed in duplicate. The results are expressed as means \pm SD $(n=2-4)$. Data were evaluated for statistically significant differences using the Bonferroni test for differences between groups. The overall significance was determined using a one-way ANOVA (repeated measures). A $p$-value of $<0.05$ was considered to be statistically significant.

\section{Results}

\subsection{Effect of Coating Condition on OSCC Cell Proliferation}

Coating with collagen type I and HFN significantly enhanced cell proliferation of SQUU-A and SQUU-B cells by approximately double when compared with negative control (Figure 1). Meanwhile, SQUU-A and SQUU-B cell proliferation on Matrigel, Laminin, poly-L-Lysine, orpoly-D-Lysine coating was nearly equal to control (Figure 1(A) and Figure 1(B)). SAS and NA cells proliferated equally well under all coating conditions (Figure 1(C) and Figure 1(D)). IC 50 values for imatinib on Matrigel, Laminin, poly-L-Lysine, and poly-D-Lysine coatings were unable to be evaluated given the poor cell proliferation on these surfaces. Therefore, collagen type I and HFN coated plates were used to evaluate $\mathrm{IC}_{50}$ values of imatinib in OSCC cells.

Representative microscopic images of SQUU-A and SQUU-B cells are shown in Figure 2. Collagen type I and HFN significantly enhanced cell proliferation compared with negative control in SQUU-A and SQUU-B cultures. These results are consistent with of the findings from WST-8 assays depicted in Figure 1(A) and Figure $1(B)$.

\subsection{Effect of the Number of Cells Seeded on OSCC Cell Proliferation}

In general, absorbance values obtained following addition of WST-8 dye correlated with the number of cells 

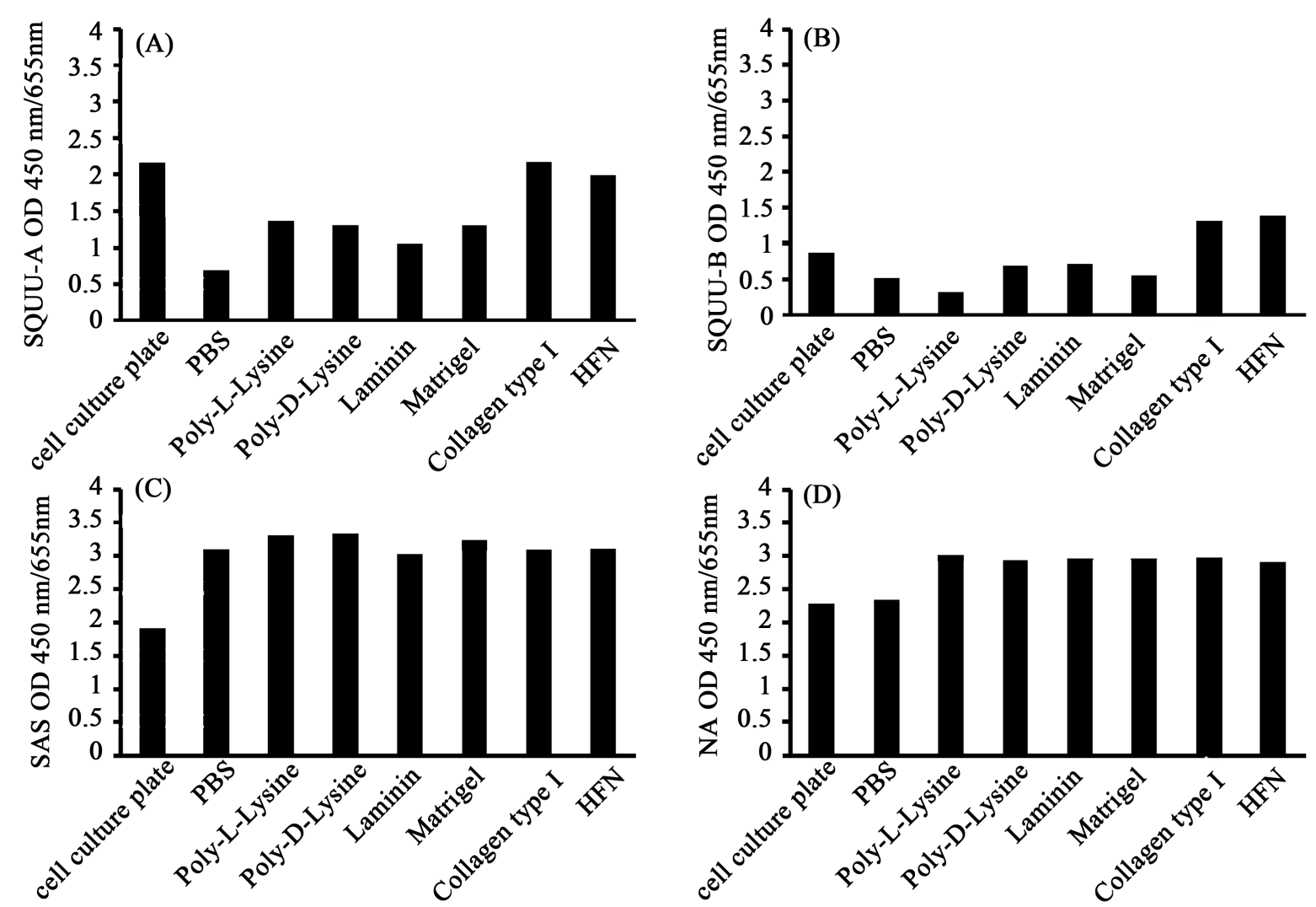

Figure 1. Effects of coating conditions using components of extracellular matrix (ECM) on cell proliferation. After coating, oral squamous cell carcinoma cells were incubated for $24 \mathrm{~h}$. Absorbance values were measured following seeding of OSCCs to culture plates coated with various ECM components. Results from SQUU-A (A), SQUU-B (B), SAS (C), and NA (D) cells. Data are presented as means \pm SD $(n=2)$.
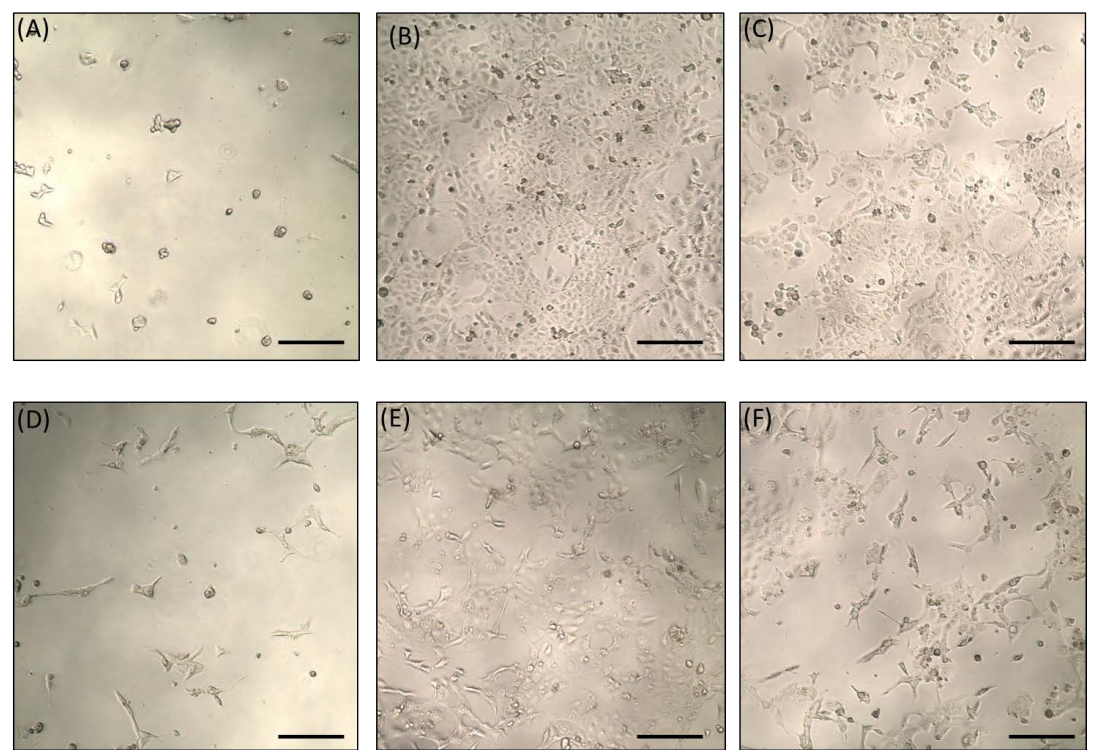

Figure 2. Microscopic images of SQUU-A and SQUU-B cells in plates coated with different extracellular matrix components. Cell proliferation was assessed by microscope after $24 \mathrm{~h}$ incubation. Representative images of SQUU-A and SQUU-B cells in plates coated with collagen type I and HFN are shown. Microscopic images of SQUU-A cells in plates coated with PBS (A), collagen type I (B), and HFN (C) are shown. Microscopic images of SQUU-B cells cultured in plates coated with PBS (D), collagen type I (E), and HFN (F). Scale bar: $300 \mu \mathrm{m}$. 
present (Figure 3). In all OSCC cell lines, absorbance values increased as the number of cells seeded increased. Furthermore, good cell proliferation was observed in all coating conditions.

From these results, $10 \times 10^{3}$ cells/well was selected as the optimal number of cells to seed for examination of imatinib $\mathrm{IC}_{50}$ values.

\subsection{Examination of Imatinib IC 50 Values in OSCC Cells}

$\mathrm{IC}_{50}$ values forimatinib in OSCC cells are presented in Table 1. Cell culture plates without coating were used as a control. Absorbance values following treatment with various concentrations of imatinib are shown in Figure 4. Absorbance values from OSCC cells treated with imatinib were decreased in a dose-dependent manner. Suppression of SQUU-A and SQUU-B cell proliferation in cultures grown on collagen type I coating and treated with imatinib is also depicted in micrographs (Figure 5). This suppression of cell proliferation was observed in all OSCC cell types cultured on collagen type I and HFN coatings. However, there was no significant difference in imatinib $\mathrm{IC}_{50}$ values between collagen type I and HFN coating. These results suggest that $\mathrm{IC}_{50}$ values were not affected by coating condition.

Table 1. Summary of $\mathrm{IC}_{50}$ values in oral squamous cell carcinoma cells under collagen type I or HFN coating condition. Data are presented as means \pm SD $(n=3)$.

\begin{tabular}{cccc}
\hline Cell line & Cell culture & Collagen type I & HFN \\
\hline SQUU-A & $54.45 \pm 2.86$ & $60.01 \pm 6.79$ & $70.69 \pm 5.16$ \\
SQUU-B & $61.53 \pm 4.05$ & $57.06 \pm 4.89$ & $69.98 \pm 7.48$ \\
SAS & $51.64 \pm 2.25$ & $48.35 \pm 3.28$ & $54.18 \pm 3.44$ \\
NA & $50.49 \pm 2.07$ & $56.34 \pm 6.67$ & $56.85 \pm 2.43$ \\
\hline
\end{tabular}
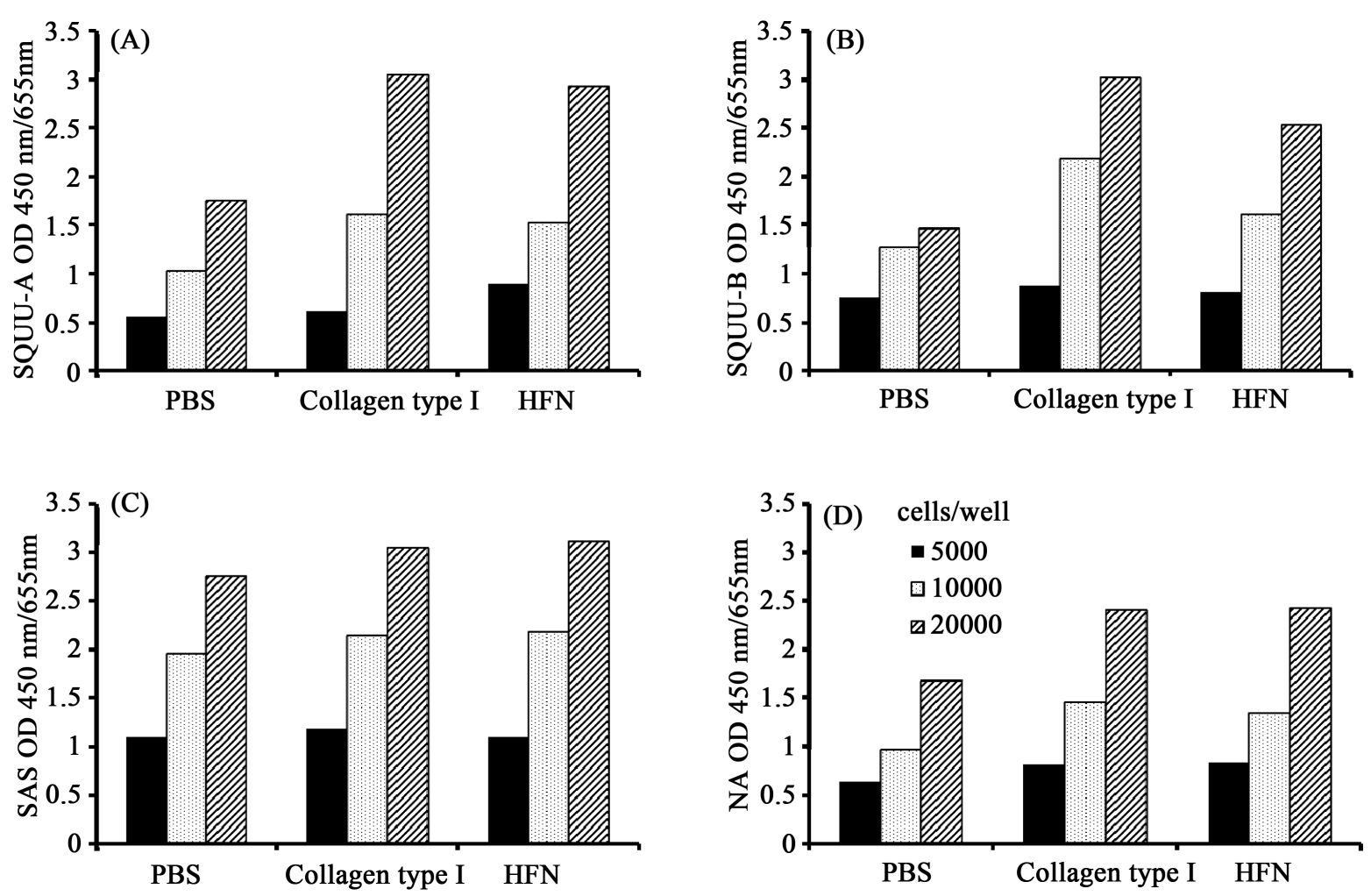

Figure 3. Effects of seeding cell number on cell proliferation. After coating, oral squamous cell carcinoma were incubated for $24 \mathrm{~h}$ on plates coated with collagen type I or HFN. Results from SQUU-A (A), SQUU-B (B), SAS (C), and NA (D) cells are shown. Data are presented as means $\pm \operatorname{SD}(n=2)$. 

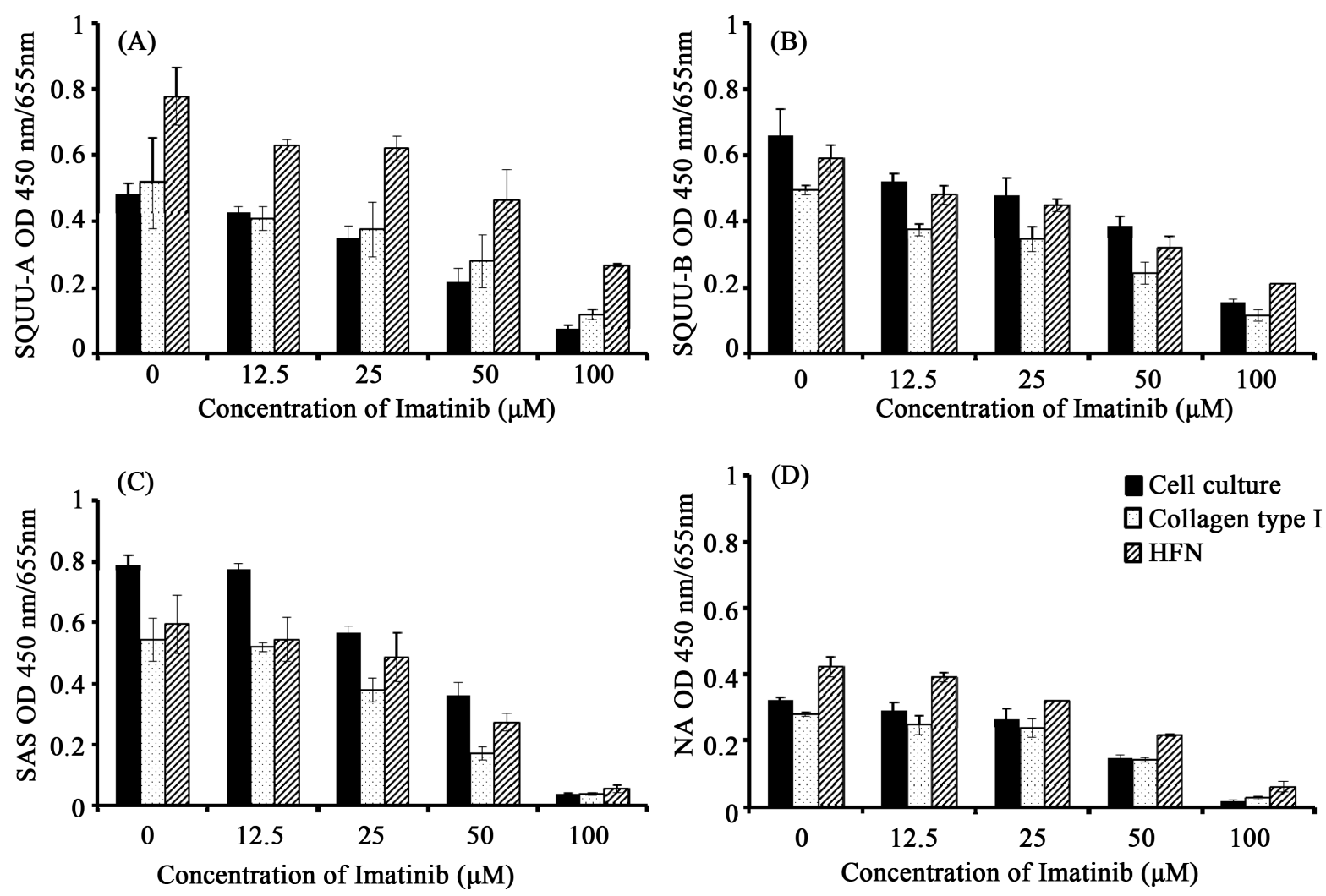

Figure 4. Absorbance values from WST-8 assay analysis of oral squamous cell carcinoma (OSCC) cells treated with imatinib under collagen type I or Human Fibronectin (HFN) coating conditions. OSCCs were incubated for $24 \mathrm{~h}$ after treatment with imatinib. Absorbance values following treatment of OSCCs with imatinib under collagen type I or HFN coating conditions are shown. Results from SQUU-A (A), SQUU-B (B), SAS (C), and NA (D) cells are shown. Data are presented as means \pm SD $(n=3)$.
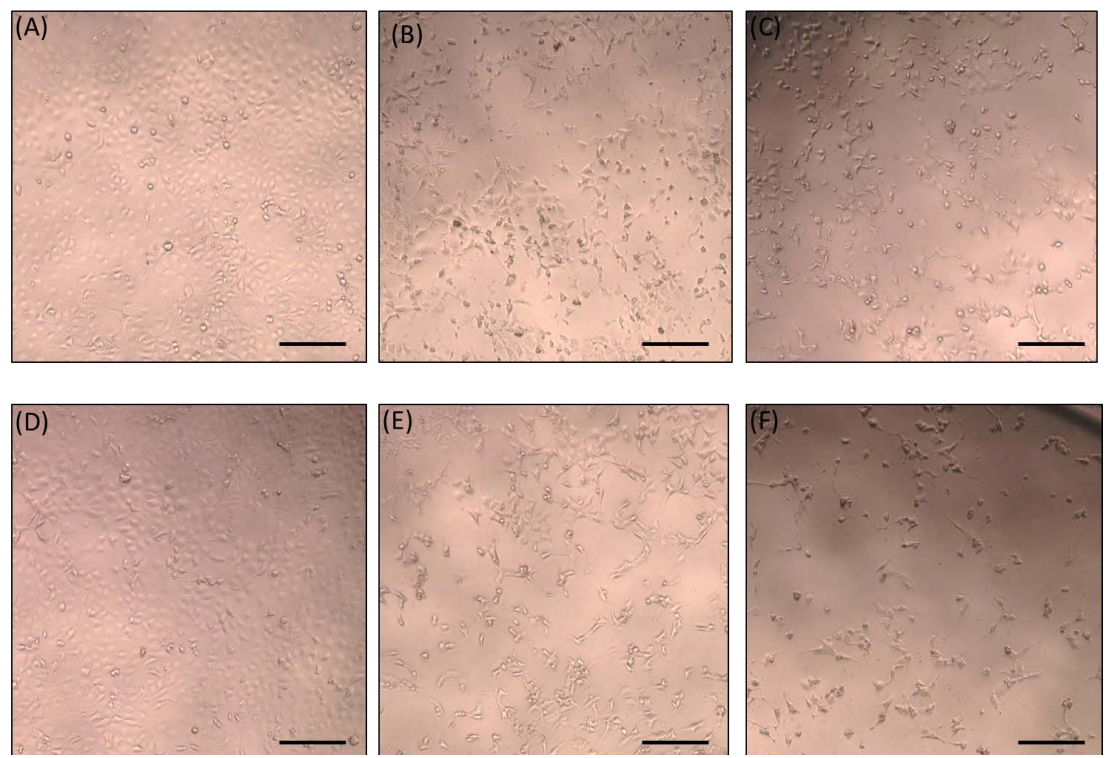

Figure 5. Microscopic images of SQUU-A and SQUU-B cells treated with imatinib under collagen type I coating condition. Representative images of SQUU-A cells treated with imatinib at 0,25 , and $50 \mu \mathrm{M}$ under collagen type I conditions are shown in (A), (B), and (C), respectively. Representative images of SQUU-B cells treated with imatinib at 0, 25, and 50 $\mu \mathrm{M}$ under collagen type I conditions are shown in (D), (E), and (F), respectively. Scale bar: $300 \mu \mathrm{m}$. 


\section{Discussion}

In this study, we coated tissue culture plates with multiple different ECM components that are associated with cell proliferation and cell adhesion and evaluated whether these coatings affected OSCC cell proliferation. We also examined the effect of imatinib on OSCC cell proliferation and determined $\mathrm{IC}_{50}$ values for imatinib in OSCC cells cultured on plates coated with collagen type I or HFN.

HFN and collagen type I have important roles in cell proliferation and cell adhesion. HFN is a large glycoprotein of 210 - $250 \mathrm{kDa}$ that possesses an Arg-Gly-Asp (RGD) peptide sequence. The RGD motif functions in cell adhesion and cellular extension by binding to integrins on the cell surface. Humans possess four classes of fibronectin: plasma fibronectin, cellular fibronectin, fetal fibronectin, and single-chain fibronectin; with cellular fibronectins playing an especially important role in cell adhesion [21]-[24]. Collagen is the most abundant protein in the human body, accounting for approximately $30 \%$ of total body protein. Collagen comprises severalgroups of proteins which are classified according to their structure, though all adopt a triple helix formation. There are more than 30 individual forms of collagen, but types I, II, and III account for $80 \%-90 \%$ of the total. Collagen type I exists in the skin, bones, and other connective tissues, where it functions in cell adhesion, proliferation, and differentiation [25]-[30].

Imatinib inhibits the proliferation of CML cells by inhibiting Bcr-Abl TK function. Imatinib also inhibits other TK receptors such as PDGF and KIT [5]-[7]. PDGF $\alpha$-dependent ECM and HGF production in fibroblasts promotes remodeling of connective tissue [31]. Additionally, imatinib reduces production of ECM and prevents development of experimental dermal fibrosis [32]. Taken together, these reports suggest that ECM components can influence the expression of PDGFR. Therefore, the sensitivity of OSCC cells to imatinib may be influenced by cell environment factors such as culture plate coating material.

We found that collagen type I and HFN could effectively promote cell proliferation in OSCC cells, and there was no significant difference in $\mathrm{IC}_{50}$ values of imatinib. This is the first report describing dose-dependent imatinib-mediated cytotoxicity in OSCC cells. However, the mechanism underlying this cytotoxicity remains unknown. We used PCR to determine that PDGFR was present only on SAS cells and KIT was present only on SQUU-A cells (data not shown). These results suggest that imatinib promotes OSCC cell toxicity through a mechanism other than TK inhibition. There may have been no significant change in imatinib $\mathrm{IC}_{50}$ values between the different coating conditions because of this as-yet unidentified cytotoxicity mechanism in OSCC cells. These results demonstrate that some molecular target drugs exhibit cancer cell cytotoxicity without being influenced by cell environment factors.

We used WST-8 to evaluate cytotoxicity assay in this study. WST-8 measures the level of formazan pigment reduced by dehydrogenase in the mitochondria. The amount of formazan dye generated by active mitochondria is proportional to the number of living cells. Other evaluation assays which evaluate cell adhesion, such as the CytoSelect ${ }^{\mathrm{TM}}$ cell adhesion assay (COSMO BIO Co, Ltd., Tokyo, Japan) or the xCELLigence System (ACEA Bioscience Inc., San Diego, CA, USA), may generate different results.

\section{Conclusion}

Collagen type I and HFN significantly enhanced OSCC cell proliferation compared with control. IC $_{50}$ values were calculated when cells were seeded to culture plates coated with collagen type I or HFN at $10 \times 10^{3}$ cells/ well. Furthermore, this study was the first to demonstrate imatinib-mediated cytotoxicity in OSCC cells. However, there were no significant changes in $\mathrm{IC}_{50}$ values between collagen type I and HFN. These results indicated that some molecular target drugs exhibited cancer cell cytotoxicity without the influence of cell environment factors. In future experiments, we will examine $\mathrm{IC}_{50}$ values for imatinib in OSCCs when combined with other anti-cancer agents such as 5-FU, cisplatin, and docetaxel in OSCCs. Furthermore, we will investigate the pharmacological mechanism underlying imatinib-mediated cytotoxicity in OSCC cells. We hope that these results will aid the identification of molecular target drugs for use in OSCC clinical chemotherapy.

\section{Conflict of Interest}

The authors declare no conflicts of interest in this study.

\section{References}

[1] Nwizu, T. aand Adelstein, D. (2015) Pharmacotherapy of Head and Neck Cancer. Expert Opinion on Pharmacotherapy, 
16, 2409-2422. http://dx.doi.org/10.1517/14656566.2015.1085507

[2] Vanderveken, O.M., Szturz, P., Specenier, P., Merlano, M.C., Bennaso, M., Van Gestel, D., Wouters, K., Van den Weygaert, D., Peeters, M. and Vermorken, J. (2016) Gemcitabine-Based Chemoradiation in the Treatment of Locally Advanced Head and Neck Cancer: Systematic Review of Literature and Meta-Analysis. Oncologist, 21, 59-71. http://dx.doi.org/10.1634/theoncologist.2015-0246

[3] Tsukagoshi, S. (1997) Development of New Anticancer Drugs-The Historical Background and Current Status in Japan. YAKUGAKU ZASSHI, 117, 875-883.

[4] Yamori, T. (2006) Overview of Molecular Target-Based Drugs. Drug Delivery System, 21, 18-23. http://dx.doi.org/10.2745/dds.21.18

[5] Toga, W., Kondo, M. and Tokoro, A. (2003) Preclinical and Clinical Profile of Imatinib Mesylate, a Potent Protein-Tyrosine Kinase Inhibitor for CML Therapy. Nihon Yakurigaku Zasshi, 121, 119-128. http://dx.doi.org/10.1254/fpj.121.119

[6] Grebien, F., Hantschel, O., Wojcik, J., Kaupe, I., Kovacic, B., Wyrzucki, A.M., Gish, G.D., Cerny-Reiterer, S., Koide, A., Beug, H., Pawson, T., Valent, P., Koide, S. and Superti-Furga, G. (2011) Targeting the SH2-Kinase Interface in Bcr-Abl Inhibits Leukemogenesis. Cell, 147, 306-319. http://dx.doi.org/10.1016/j.cell.2011.08.046

[7] Buchdunger, E., Zimmermann, J., Mett, H., Meyer, T., Müller, M., Druker, B.J. and Lydon, N.B. (1996) Inhibition of the Abi Protein-Tyrosine Kinase in Vitro and in Vivo by a 2-Phenylaminopyrimidine Derivative. Cancer Research, 56, 100-104.

[8] Yamakawa, Y., Hamada, A., Uchida, T., Sato, D., Yuki, M., Hayashi, M., Kawaguchi, T. and Saito, H. (2014) Distinct Interaction of Nilotinib and Imatinib with P-Glycoprotein in Intracellular Accumulation and Cytotoxicity in CML Cell Line K562 Cells. Biological and Pharmaceutical Bulletin, 37, 1330-1335. http://dx.doi.org/10.1248/bpb.b14-00254

[9] Jin, T., Nakatani, T., Taguchi, T., Sonobe, H., Morimoto, N., Sugimoto, T., Akimori, T., Nakano, T., Namikawa, T., Okabayashi, T., Kobayashi, M. and Araki, K. (2006) Thapsigargin Enhances Cell Death in the Gastrointestinal Stromal Tumor Cell Line, GIST-T1, by Treatment with Imatinib (Glivec). Journal of Health Sciences, 52, 110-117. http://dx.doi.org/10.1248/jhs.52.110

[10] Davis, G.E. and Senger, D.R. (2015) Endothelial Extracellular Matrix: Biosynthesis, Remodeling, and Functions during Vascular Morphogenesis and Neovessel Stabilization. Circulation Research, 97, 1093-1107. http://dx.doi.org/10.1161/01.RES.0000191547.64391.e3

[11] Martin, P. (1997) Wound Healing-Aiming for Perfect Skin Regeneration. Science, 276, 75-81. http://dx.doi.org/10.1126/science.276.5309.75

[12] Monine, M.I. and Haugh, J.M. (2008) Cell Population-Based Model of Dermal Wound Invasion with Heterogeneous Intracellular Signaling Properties. Cell Adhesion \& Migration, 2, 137-145. http://dx.doi.org/10.4161/cam.2.2.6511

[13] Damiano, J.S., Cress, A.E., Hazlehurst, L.A., Shtil, A.A. and Dalton, W.S. (1999) Cell Adhesion Mediated Drug Resistance (CAM-DR): Role of Integrins and Resistance to Apoptosis in Human Myeloma Cell Lines. Blood, 93, 16581667.

[14] Morifuji, M., Taniguchi, S., Sakai, H., Nakabeppu, Y. and Ohishi, M. (2000) Differential Expression of Cytokeratin after Orthotopic Implantation of Newly Established Human Tongue Cancer Cell Lines of Defined Metastatic Ability. American Journal of Pathology, 156, 1317-1326. http://dx.doi.org/10.1016/S0002-9440(10)65002-X

[15] Takahashi, K., Kanazawa, H., Akiyama, Y., Tazaki S., Takahara, M., Muto, T., Tanzawa, H. and Sato, K. (1989) Establishment and Characterization of a Cell Line (SAS) from Poorly Differentiated Human Squamous Cell Carcinoma of the Tongue. Journal of The Japanese Stomatological Society, 38, 20-28.

[16] Hung, C.M., Chang, C.C., Lin, C.W., Ko, S.Y. and Hsu, Y.C. (2013) Cucurbitacin E as Inducer of Cell Death and Apoptosis in Human Oral Squamous Cell Carcinoma Cell Line SAS. International Journal of Molecular Sciences, 14, 17147-17156. http://dx.doi.org/10.3390/ijms140817147

[17] Chen, Y.W., Huang, H.S., Shieh, Y.S., Ma, K.H., Huang, S.H., Hueng, D.Y., Sytwu, H.K. and Lin, G.J. (2014) A Novel Compound NSC745885 Exerts Anti-Tumor Effect on Tongue Cancer SAS Cells in Vitro and in Vivo. PLoS ONE, 9, e113703. http://dx.doi.org/10.1371/journal.pone.0104703

[18] Yoshiya, M. (1990) A Fibronectin-Producing Cell Line Established from a Human Squamous Cell Carcinoma of the Tongue and Its Characterization. Japanese Journal of Oral and Maxillofacial Surgery, 36, 868-880. http://dx.doi.org/10.5794/jjoms.36.868

[19] Kleinman, H.K., Klebe, R.J. and Martin, G.R. (1981) Role of Collagenous Matrices in the Adhesion and Growth of Cells. The Journal of Cell Biology, 88, 473-485. http://dx.doi.org/10.1083/jcb.88.3.473

[20] Yao, J.C., Zhang, J.X., Rashid, A., Yeung, S.C., Szklaruk, J., Hess, K., Xie, K., Ellis, L., Abbruzzese, J.L. and Ajani, J.A. (2007) Clinical and in Vitro Studies of Imatinib in Advanced Carcinoid Tumors. Clincal Cancer Research, 13, 234-240. http://dx.doi.org/10.1158/1078-0432.CCR-06-1618 
[21] Colombo, E., Calcaterra, F., Cappelletti, M., Mavilio, D. and Bella, S.D. (2013) Comparison of Fibronectin and Collagen in Supporting the Isolation and Expansion of Endothelial Progenitor Cells from Human Adult Peripheral Blood. PLoS ONE, 8, e66734. http://dx.doi.org/10.1371/journal.pone.0066734

[22] Koide, A., Wojcik, J., Gilbreth, R.N., Hoey, R.J. and Koide, S. (2012) Teaching an Old Scaffold New Tricks: Monobodies Constructed Using Alternative Surfaces of the FN3 Scaffold. Journal of Molecular Biology, 415, 393-405. http://dx.doi.org/10.1016/j.jmb.2011.12.019

[23] Xu, J., Bae, E., Zhang, Q., Annis, D.S., Erickson, H.P. and Mosher, D.F. (2009) Display of Cell Surface Sites for Fibronectin Assembly Is Modulated by Cell Adherence to ${ }^{1} \mathrm{~F} 3$ and C-Terminal Modules of Fibronectin. PLoS ONE, 4, e4113. http://dx.doi.org/10.1371/journal.pone.0004113

[24] Aota, S., Nagai, T. and Yamada, K.M. (1991) Characterization of Regions of Fibronectin besides the Arginine-Glycine-Aspartic Acid Sequence Required for Adhesive Function of the Cell-Binding Domain Using Site-Directed Mutagenesis. The Journal of Biological Chemistry, 266, 15938-15943.

[25] Ricard-Blum, S. and Ruggiero, F. (2005) The Collagen Superfamily: From the Extracellular Matrix to the Cell Membrane. Pathologie Biologie, 53, 430-442. http://dx.doi.org/10.1016/j.patbio.2004.12.024

[26] Kadler, K.E., Baldock, C., Bella, J. and Boot-Handford, R.P. (2007) Collagens at a Glance. Journal of Cell Science, 120, 1955-1958. http://dx.doi.org/10.1242/jcs.03453

[27] Yamada, K.M., Ohanian, S.H. and Pastan, I. (1976) Cell Surface Protein Decreases Microvilli and Ruffles on Transformed Mouse and Chick Cells. Cell, 9, 241-245. http://dx.doi.org/10.1016/0092-8674(76)90115-X

[28] Yang, N.S., Kube, D., Park, C. and Furmanski, P. (1981) Growth of Human Mammary Epithelial Cells on Collagen Gel Surfaces. Cancer Research, 41, 4093-4100.

[29] Whelan, M.C. and Senger, D.R. (2003) Collagen I Initiates Endothelial Cell Morphogenesis by Inducing Actin Polymerization through Suppression of Cyclic AMP and Protein Kinase A. The Journal of Biological Chemistry, 278, 327334. http://dx.doi.org/10.1074/jbc.M207554200

[30] Kokenyesi, R., Murray, K.P., Benshushan, A., Huntley, E.D. and Kao, M.S. (2003) Invasion of Interstitial Matrix by a Novel Cell Line from Primary Peritoneal Carcinosarcoma, and by Established Ovarian Carcinoma Cell Lines: Role of Cell-Matrix Adhesion Molecules, Proteinases, and E-Cadherin Expression. Gynecologic Oncology, 89, 60-72. http://dx.doi.org/10.1016/S0090-8258(02)00152-X

[31] Horikawa, S., Ishii, Y., Hamashima, T., Yamamoto, S., Mori, H., Fujimori, S., Shen, J., Inoue, R., Nishizono, H., Itoh, H., Majima, M., Abraham, D., Miyawaki, T. and Sasahara, M. (2015) PDGFR $\alpha$ Plays a Crucial Role in Connective Tissue Remodeling. Scientific Reports, 5, Article No. 17948. http://dx.doi.org/10.1038/srep17948

[32] Distler, J.H., Jungel, A., Huber, L.C., Schulze-Hoesel, U., Zwerina, J., Gay, R.E., Michel, B.A., Hauser, T., Schett, G., Gay, S. and Distler, O. (2007) Imatinib Mesylate Reduces Production of Extracellular Matrix and Prevents Development of Experimental Dermal Fibrosis. Arthritis \& Rheumatism, 56, 311-322. http://dx.doi.org/10.1002/art.22314

\section{Submit or recommend next manuscript to SCIRP and we will provide best service for you:}

Accepting pre-submission inquiries through Email, Facebook, Linkedin, Twitter, etc

A wide selection of journals (inclusive of 9 subjects, more than 200 journals)

Providing a 24-hour high-quality service

User-friendly online submission system

Fair and swift peer-review system

Efficient typesetting and proofreading procedure

Display of the result of downloads and visits, as well as the number of cited articles

Maximum dissemination of your research work

Submit your manuscript at: http://papersubmission.scirp.org/ 